\section{(6)} OPEN ACCESS

\title{
Sociodemographic and behavioural correlates of lifetime number of sexual partners: findings from the English Longitudinal Study of Ageing
}

\author{
Sarah E Jackson, ${ }^{1}$ Lin Yang, ${ }^{2}$ Nicola Veronese, ${ }^{3}$ Ai Koyanagi, ${ }^{4}$ \\ Guillermo Felipe López Sánchez, ${ }^{\circ}$ Igor Grabovac, ${ }^{6}$ Pinar Soysal, ${ }^{7}$ \\ Lee Smith ${ }^{8}$
}

For numbered affiliations see end of article.

\section{Correspondence to} Dr Lee Smith, Cambridge Centre for Sport and Exercise Sciences, Anglia Ruskin University, Cambridge, UK, CB1 1PT; lee. smith@anglia.ac.uk

Received 11 September 2018 Revised 12 December 2018 Accepted 5 February 2019 Published Online First 4 March 2019
Check for updates

(c) Author(s) (or their employer(s)) 2019. Re-use permitted under CC BY-NC. No commercial re-use. See rights and permissions. Published by BMJ.

To cite: Jackson SE, Yang $\mathrm{L}$, Veronese N, et al. BMJ Sex Reprod Health

2019;45:138-146.

\section{ABSTRACT}

Background No current data are available on correlates of lifetime sexual partners at older ages. This study aimed to explore correlates of the lifetime number of sexual partners in a sample of older adults.

Method Data were from 3054 men and 3867 women aged $\geq 50$ years participating in the English Longitudinal Study of Ageing. Participants reported their lifetime number of sexual partners and a range of sociodemographic characteristics and health behaviours.

Multivariable multinomial logistic regression was used to examine correlates of lifetime number of sexual partners, with analyses performed separately for men and women and weighted for non-response.

Results Younger age, being separated/divorced or single/never married, being a current or former smoker, and drinking alcohol regularly or frequently were independently associated with a higher number of sexual partners in both men and women. Homosexuality in men and bisexuality in women were also associated with a higher number of sexual partners. White ethnicity, regular moderate and vigorous physical activity, and the absence of limiting longstanding illness were independently associated with a higher number of sexual partners in women only, and being in the highest and lowest quintiles of wealth was independently associated with a higher number of sexual partners in men only.

Conclusions A higher lifetime number of sexual partners is associated with a number of sociodemographic and behavioural factors. An understanding of who is more likely to have had more sexual partners may help health practitioners to identify individuals who are at greatest risk of sexually transmitted infection and

\section{Key messages}

- The number of sexual partners a person has in their lifetime is an important predictor of sexually transmitted infection (STI) and their associated health risks.

- Until now, no current data are available on correlates of lifetime sexual partners at older ages.

- We found in a large representative sample of older English adults that a higher lifetime number of sexual partners is associated with a number of sociodemographic and behavioural factors.

- An understanding of who is more likely to have had more sexual partners may help health practitioners to identify individuals who are at greatest risk of STI and their associated health complications across the life course.

their associated health complications across the life course.

\section{BACKGROUND}

The number of sexual partners a person has in their lifetime is an important correlate of sexually transmitted infections (STIs) and their associated health risks. ${ }^{1-5}$ With the exception of HIV and AIDS, the general population is largely unaware of the substantial impact STIs can have on morbidity and mortality. ${ }^{6}$ For example, a number of sexually transmitted pathogens are known to cause cancer. Sexually acquired human papillomavirus (HPV) plays a causal role in around $70 \%$ of cervical, vaginal and anal cancers, $30 \%-40 \%$ of vulval, penile and oropharyngeal cancers, and has been 
causally linked to non-melanoma skin cancer and cancer of the conjunctiva. ${ }^{7}$ Hepatitis B virus causes hepatocellular carcinoma, one of the most common forms of cancer. ${ }^{8}$ Other STIs associated with cancers include Epstein-Barr virus, linked to nasopharyngeal carcinoma and lymphoma; human herpes virus type 8, linked to Kaposi's sarcoma ${ }^{9}$; and human T-cell lymphotrophic virus type I (HTLV-I), linked to adult T-cell leukaemia and lymphoma. ${ }^{10}$ STIs also increase the risk of infertility $^{11}$ and are associated with acute complications for pregnant women and their infants, such as miscarriage, prematurity, stillbirth and newborn blindness. ${ }^{12} 13$ STIs are the leading cause of loss of healthy life years in developing countries, ${ }^{13}$ and account for a substantial number of adverse health events and deaths globally. For example, in 1998 around 20 million adverse health events and almost 30000 deaths in the US were directly attributable to STIs. ${ }^{14}$

The significant health consequences associated with STIs, and the high costs to society in terms of healthcare expenditure, ${ }^{15}$ underscore the importance of identifying those at risk of STI and implementing effective prevention strategies. There is a relatively large literature base on the correlates of number of sexual partners in adolescents. For example, the Youth Risk Behaviour Surveillance System in the US has observed significant associations with sex and ethnicity, with male students (20.9\%) more likely than female students (14.4\%), and black students (35.6\%) more likely than white and Hispanic students $(14.2 \%$ and $17.6 \%$, respectively), to have had four or more sexual partners during their lifetime. ${ }^{16}$ Another US-based study found that common correlates of number of sexual partners among black females include alcohol, tobacco, marijuana use, and dating violence; and white females had similar correlates with the addition of physical fighting. ${ }^{17}$ Among white males, alcohol, tobacco, marijuana use, physical fighting, carrying weapons, and dating violence were strong correlates of number of sexual partners; and black males had similar correlates with the addition of binge alcohol use. ${ }^{17}$

While these findings provide important information for the development of interventions to reduce risky sexual behaviour at younger ages, factors that predict the number of lifetime sexual partners in adolescence may differ from those associated with a higher number of lifetime sexual partners in older adults. It is possible that individuals with a relatively high number of sexual partners in adolescence may have an average or below-average number by the time they reach old age, as others 'catch up' over time; for example, by remaining single and continuing to date while others settle down and stay with a single partner. Some literature exists on correlates of lifetime number of sexual partners in general adult populations, for example, in a British sample of 4913 men and 6777 women (aged 16 to 74 years) it was found that in women, but not men, low sexual function was associated with a higher number of sexual partners. ${ }^{18}$ To our knowledge, no current data are available on correlates of lifetime sexual partners at older ages. This information is needed as older adults are at greatest risk of developing cancer $^{19}$ and many cancers that are common in older adults have been shown to be associated with STIs (eg, liver, anus, penile, sarcoma, prostate). Moreover, HIV diagnosis in later life is associated with shorter survival periods. ${ }^{20}$ In addition, a focus on older people, who have had increased opportunity for sexual experience on the basis of having had more time during which they have or could have been sexually active, would offer greater insight into factors predictive of a higher number of sexual partners that may aid in the identification of those at greatest risk of STIs across the life course. The identification of correlates of lifetime number of sexual partners in older adults would also offer insight as to how interventions could best be targeted to educate younger adults about the risks associated with having a high number of sexual partners and the practice of safe sex.

This study therefore aimed to explore correlates of the lifetime number of sexual partners in a nationally representative sample of older adults (aged $\geq 50$ years). We examined associations between self-reported lifetime number of sexual partners and a range of sociodemographic and behavioural variables.

\section{METHOD}

\section{Study population}

Data were from the English Longitudinal Study of Ageing (ELSA), a population-representative longitudinal panel study of men and women aged $\geq 50$ years living in England. ${ }^{21}$ The study started in 2002, with participants recruited from an annual cross-sectional survey of households and followed up every 2 years. Data are collected via computer-assisted personal interview (CAPI) conducted face-to-face in the participant's home or residence, with additional self-completion questionnaires returned to the research office by post after the CAPI. The Sexual Relationships and Activities Questionnaire (SRA-Q) was administered as a self-completion measure in Wave $6(2012 / 13)$ and was returned by 7079 (67\%) participants. Of these, 6921 reported their lifetime number of sexual partners and formed the final analytical sample. All participants gave full informed consent to participate in the study, and ethical approval was obtained from the London Multi-Centre Research Ethics Committee.

\section{Measures}

Number of sexual partners was assessed as part of the SRA-Q, ${ }^{22}$ which participants completed in private and returned in a sealed envelope. Participants were asked to indicate the number of sexual partners (vaginal/oral/anal sex) they had had in their lifetime $(0,1,2-4,5-9,10-19$, $20+$ ). Due to low numbers of participants reporting have had 0 or in excess of 20 partners, we combined 
these with proximal categories, leaving four groups for analysis: $0-1,2-4,5-9$ and $\geq 10$ sexual partners.

Demographic information collected included age, sex, ethnicity (white vs. non-white) and partnership status (married/cohabiting, separated/divorced, widowed, or single/never married). Socioeconomic status was based on household non-pension wealth (which has been identified as particularly relevant to health outcomes in this age group ${ }^{23}$ ), categorised into quintiles across all Wave 6 ELSA participants.

Sexual orientation was assessed with the question: "Which statement best describes your sexual desires over your lifetime? Please include being interested in sex, fantasising about sex or wanting to have sex". Response options were (1) entirely for women, (2) mostly for women, but some desires for men, (3) equally for women and men, (4) mostly for men, but some desires for women, (5) entirely for men, and (6) no sexual desires in lifetime. We categorised participants with desires entirely for a different sex as heterosexual, entirely for the same sex as homosexual and those endorsing response options 2, 3 or 4 as bisexual. We coded the sexual orientation of those reporting no sexual desires as missing.

Health-related variables included self-reported smoking status (current smoker, former smoker or never smoker) and frequency of alcohol intake, categorised as never/rarely (never - once or twice a year), regularly (once every couple of months - twice a week), or frequently (3 days a week - almost every day). ${ }^{22}$ Physical activity was assessed with three items that asked participants how often they took part in vigorous, moderate and low-intensity activities (more than once a week, once a week, 1-3 times a month, hardly ever/never), ${ }^{24}$ and further categorised into three groups, as previously described: ${ }^{25}$ inactive (no moderate/vigorous activity on a weekly basis); moderate activity at least once a week; and vigorous activity at least once a week. Limiting longstanding illness was self-reported in response to two questions: (i) "Do you have any long-standing illness, disability, or infirmity? By long-standing I mean anything that has troubled you over a period of time or that is likely to affect you over a period of time". If yes, (ii) "Does this illness or disability limit your activities in any way?". Declaration of a long-standing illness and any form of limitation classified the participant as having a limiting long-standing illness.

\section{Patient and public involvement}

Patients and public were not involved in the design of any aspect of this observational study.

\section{Statistical analysis}

Analyses were performed using IBM SPSS Statistics 22. Data were weighted to correct for sampling probabilities and for differential non-response and to calibrate back to the 2011 National Census population distributions for age and sex. The weights accounted for the differential probability of being included in Wave 6 of
ELSA and for non-response to the SRA-Q. Details can be found at http://doc.ukdataservice.ac.uk/doc/5050/ $\mathrm{mrdoc} / \mathrm{pdf} / 5050$ _elsa_w6_technical_report_v1.pdf.

Bivariate associations between lifetime number of sexual partners and predictors were assessed using one-way analyses of variance (ANOVAs) for continuous variables and $\chi^{2}$ tests for categorical variables. We then used multivariable multinomial logistic regression to analyse independent associations between lifetime number of sexual partners and predictors, with all variables entered into the same model. Separate analyses were carried out on men and women.

We performed a sensitivity analysis in which multivariable models were repeated excluding participants who reported having had no sexual partners, to assess the extent to which their inclusion in the group with one sexual partner affected the results.

\section{RESULTS}

Among men, 29.8\% reported having had 0-1 sexual partners in their lifetime, $30.5 \%$ had had between 2 and 4 partners, $19.8 \%$ had had between 5 and 9 partners, and $19.9 \%$ had had 10 or more partners. Among women, the respective figures were $38.5 \%(0-1)$, $37.4 \%(2-4), 15.6 \%(5-9)$ and $8.5 \%(\geq 10)$.

Bivariate associations between lifetime number of sexual partners and correlates are summarised in table 1 . In both men and women, lifetime number of sexual partners was significantly associated with age, partner status, sexual orientation, wealth, smoking status, alcohol intake and physical activity. Those who had had more sexual partners tended to be younger than those who reported few sexual partners $(p<0.001)$. Those who were separated/divorced or single/never married were more likely to report a higher number of sexual partners than those who were married/cohabiting or widowed $(\mathrm{p}<0.001)$. Those who were bisexual or homosexual tended to have a higher number of sexual partners than those who were heterosexual $(\mathrm{p}<0.001)$. Those in the lowest and highest quintiles of wealth reported more sexual partners than those in the middle quintiles $(p<0.001$ in men, $p=0.006$ in women). Current and former smokers reported a higher number of sexual partners than never smokers $(\mathrm{p}<0.001)$, and regular/frequent alcohol drinkers reported a higher number of sexual partners than those who were teetotal or rarely drank alcohol $(p<0.001)$. Regular moderate/vigorous physical activity in women and regular vigorous physical activity in men was associated with a higher number of sexual partners $(\mathrm{p}<0.001)$. In women, but not in men, there was also a significant association with ethnicity, with white women reporting a higher number of sexual partners than those from ethnic minority groups $(p<0.001)$. In men, but not in women, there was a significant association with limiting long-standing illness, with men without an illness more likely to report having more than one partner $(\mathrm{p}=0.037)$. 


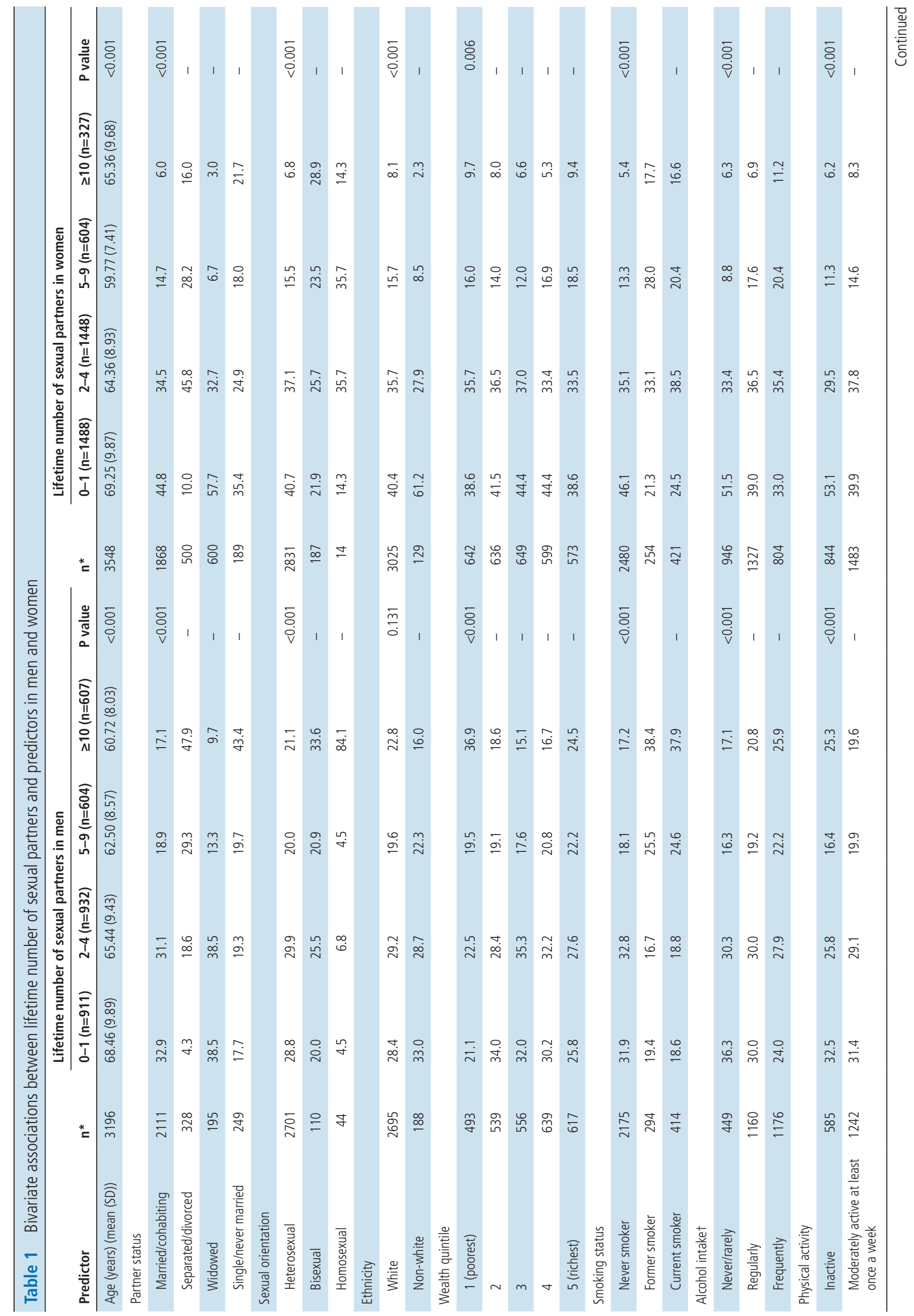




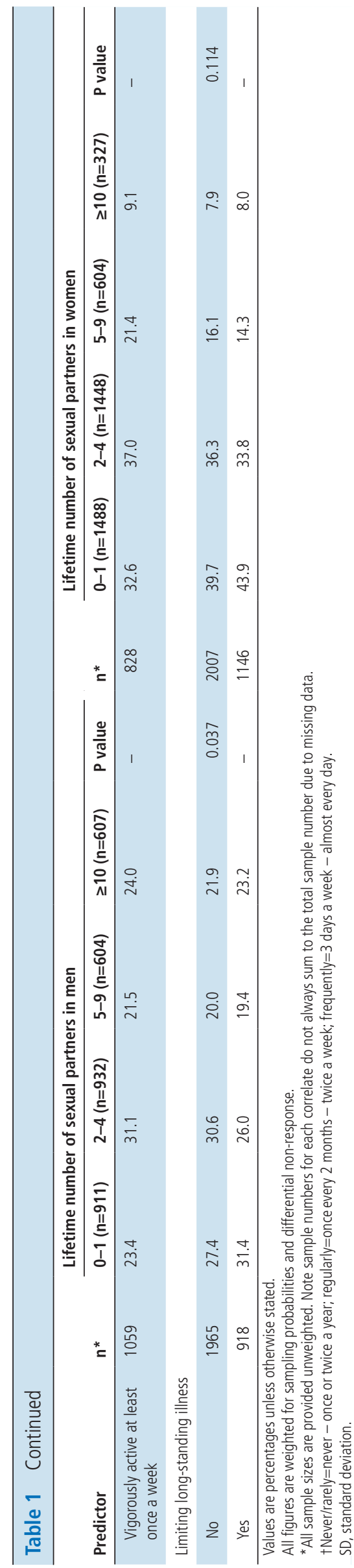

Multivariable models confirmed that in both men (table 2) and women (table 3), younger age, being separated/divorced or single/never married, being a current (and to a lesser extent former) smoker, and drinking alcohol regularly or frequently were independently associated with a higher lifetime number of sexual partners. Homosexuality in men and bisexuality in women were also independently associated with a higher number of sexual partners. In addition, white ethnicity and regular moderate and vigorous physical activity were independently associated with a higher number of sexual partners in women only, and being in the highest and lowest quintiles of wealth was independently associated with a higher number of sexual partners in men only. After adjustment, the absence of limiting long-standing illness was associated with a higher number of sexual partners in women, but not in men.

There were no notable differences in the results when men $(n=38)$ and women $(n=28)$ who reported no sexual partners were excluded (online supplementary tables 1 and 2, respectively).

\section{DISCUSSION}

Using data from a large, representative sample of older adults living in England, the present study has identified behavioural and sociodemographic factors that are associated with a greater number of lifetime sexual partners. Men were more likely than women to report a higher number of lifetime sexual partners: $39.7 \%$ of men and $24.1 \%$ of women reported having had at least five sexual partners in their lifetime, and $19.9 \%$ of men and $8.5 \%$ of women had had 10 or more partners. Despite differences in the absolute number of partners, there were a number of similarities in the factors that predicted lifetime number of sexual partners in men and women. Being younger, separated/divorced or single/never married, being a current or former smoker, and drinking alcohol regularly or frequently were independently associated with a higher number of lifetime sexual partners in both sexes. Sex-specific predictors were also observed. In men but not women, being gay and being in the highest and lowest quintiles of wealth were associated with a higher number of previous sexual partners. In women but not men, being bisexual, of white ethnicity, participating in regular vigorous physical activity and being free of limiting long-standing illness were associated with a greater number of previous sexual partners.

The finding that men have a higher number of lifetime sexual partners than women is consistent with previous research in adolescents. ${ }^{26}$ This may be driven by men's higher testosterone levels leading to increased feelings of sexual desire, ${ }^{27}$ and/or the 'sexual double standard' that sees more favourable societal attitudes towards promiscuity in males than females. ${ }^{28}$ It may also be at least partly attributable to social desirability bias, with men more likely than women to overreport the number of sexual partners they have had. ${ }^{29}$ The finding that among the over-50s, 
Table 2 Multivariable models testing independent associations between predictors and lifetime number of sexual partners in men

\begin{tabular}{|c|c|c|c|}
\hline \multirow[b]{2}{*}{ Predictor } & \multicolumn{3}{|c|}{ Lifetime number of sexual partners in men (adjusted OR $(95 \% \mathrm{Cl})) \dagger$} \\
\hline & $2-4(n=786) \ddagger$ & $5-9(n=491)$ & $\geq 10(n=486)$ \\
\hline Age & $0.96(0.95 \text { to } 0.97)^{* * *}$ & $0.94(0.92 \text { to } 0.95)^{* * *}$ & $0.92(0.91 \text { to } 0.94)^{* * *}$ \\
\hline \multicolumn{4}{|l|}{ Partnership status§ } \\
\hline Separated/divorced & $4.95(2.65 \text { to } 9.24)^{* * *}$ & $12.97(6.98 \text { to } 24.08)^{* * *}$ & $20.18(10.94 \text { to } 37.21)^{* * *}$ \\
\hline Widowed & $1.83(1.23 \text { to } 2.73)^{* *}$ & 1.38 (0.80 to 2.39$)$ & 1.47 (0.81 to 2.67$)$ \\
\hline Single/never married & 1.23 (0.77 to 1.95$)$ & $1.69(1.05 \text { to } 2.74)^{*}$ & $2.59(1.65 \text { to } 4.07)^{* * *}$ \\
\hline \multicolumn{4}{|l|}{ Sexual orientation } \\
\hline Bisexual & 0.99 (0.55 to 1.77$)$ & 0.88 (0.46 to 1.67$)$ & 1.29 (0.71 to 2.36$)$ \\
\hline Homosexual & 1.24 (0.21 to 7.46$)$ & $0.80(0.10$ to 6.50$)$ & $11.55(2.55 \text { to } 52.38)^{* *}$ \\
\hline Non-white ethnicity†† & 1.03 (0.67 to 1.59$)$ & 1.12 (0.69 to 1.82$)$ & 0.85 (0.50 to 1.46$)$ \\
\hline \multicolumn{4}{|l|}{ Wealth quintile $\neq$} \\
\hline 2 & $0.68(0.46 \text { to } 0.99)^{*}$ & $0.63(0.41 \text { to } 0.97)^{*}$ & $0.41(0.27 \text { to } 0.62)^{\star * *}$ \\
\hline 3 & $0.94(0.64$ to 1.37$)$ & $0.81(0.52$ to 1.26$)$ & $0.50(0.32 \text { to } 0.77)^{* *}$ \\
\hline 4 & $0.96(0.65$ to 1.41$)$ & 1.05 (0.68 to 1.62$)$ & $0.60(0.39 \text { to } 0.94)^{*}$ \\
\hline 5 (richest) & 0.82 (0.55 to 1.23$)$ & $1.21(0.77$ to 1.90$)$ & 0.94 (0.60 to 1.45$)$ \\
\hline \multicolumn{4}{|l|}{ Smoking status§§ } \\
\hline Former smoker & $0.54(0.35 \text { to } 0.82)^{* *}$ & 1.16 (0.77 to 1.74$)$ & 1.48 (0.99 to 2.22$)$ \\
\hline Current smoker & 0.87 (0.60 to 1.26$)$ & $1.93(1.33 \text { to } 2.80)^{* *}$ & $2.13(1.46 \text { to } 3.11)^{* * *}$ \\
\hline \multicolumn{4}{|l|}{ Alcohol intakeףी } \\
\hline Regularly & $1.10(0.81$ to 1.48$)$ & $1.51(1.04 \text { to } 2.18)^{*}$ & $1.97(1.33 \text { to } 2.92)^{* *}$ \\
\hline Frequently & 1.34 (0.98 to 1.83$)$ & $2.32(1.58 \text { to } 3.39)^{\star \star *}$ & $3.25(2.17 \text { to } 4.88)^{* * *}$ \\
\hline \multicolumn{4}{|l|}{ Physical activity††† } \\
\hline Moderately active at least once a week & 1.02 (0.76 to 1.37$)$ & 1.28 (0.90 to 1.82$)$ & 0.74 (0.52 to 1.05$)$ \\
\hline Vigorously active at least once a week & 1.30 (0.94 to 1.80$)$ & $1.59(1.08 \text { to } 2.35)^{*}$ & 1.14 (0.78 to 1.67$)$ \\
\hline Limiting long-standing illness & $0.84(0.66$ to 1.08$)$ & 1.16 (0.88 to 1.54$)$ & $1.13(0.84$ to 1.51$)$ \\
\hline
\end{tabular}

All figures are weighted for sampling probabilities and differential non-response.

${ }^{*} \mathrm{P}<0.05,{ }^{* *} \mathrm{p}<0.01,{ }^{* * *} \mathrm{p}<0.001$.

†Multivariable multinomial logistic regression was performed. 0-1 sexual partners was the reference group in all analyses $(n=775)$.

¥Unweighted sample sizes. Models were performed on complete cases and as such the analysed sample number differs from the number included in the bivariate analyses.

§Reference category: married/cohabiting.

IReference category: heterosexual.

††Reference category: white.

¥¥Reference category: 1 (poorest).

$\S \S$ Reference category: never smoker.

११ीReference category: never/rarely.

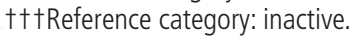

younger age was associated with a higher number of lifetime sexual partners is interesting, and likely reflects changes in attitudes and opinions towards sexuality and changes in rates of divorce and separation ${ }^{30}$ between generations, even those relatively close in age. Little has been published on older adults' attitudes towards sexuality and further work in this area is required. Perhaps unsurprisingly, those participants who were not married (separated/divorced or single/never married) reported a higher number of sexual partners. This is likely owing to greater opportunity to engage in sexual activity with multiple sexual partners throughout life, although the frequency of sexual activity reported by this population compared with those who are married is lower (data not shown).

In both sexes, smoking and alcohol use were associated with a higher number of lifetime sexual partners. Alcohol use has previously been shown to be associated with a greater number of lifetime sexual partners and a greater chance of HIV transmission. ${ }^{31}{ }^{32}$ Having a greater tendency for risk taking has been shown to be associated with smoking and alcohol consumption, ${ }^{33} 34$ and it is plausible that those who have a tendency to take risks are also likely to have a higher number of lifetime sexual partners. Moreover, alcohol consumption/being drunk affects decision-making 
Table 3 Multivariable models testing independent associations between predictors and lifetime number of sexual partners in women

\begin{tabular}{|c|c|c|c|}
\hline \multirow[b]{2}{*}{ Predictor } & \multicolumn{3}{|c|}{ Lifetime number of sexual partners in women (adjusted OR $(95 \% \mathrm{CI})) \dagger$} \\
\hline & $2-4(n=1170) \ddagger$ & $5-9(n=486)$ & $\geq 10(n=243)$ \\
\hline Age & $0.95(0.93 \text { to } 0.96)^{* * *}$ & $0.90(0.89 \text { to } 0.92)^{* * *}$ & $0.90(0.88 \text { to } 0.92)^{* * *}$ \\
\hline \multicolumn{4}{|l|}{ Partnership status§ } \\
\hline Separated/divorced & $6.98(4.84 \text { to } 10.07)^{* * *}$ & $12.68(8.39 \text { to } 19.16)^{* * *}$ & $14.53(8.99 \text { to } 23.46)^{* * *}$ \\
\hline Widowed & $1.73(1.33 \text { to } 2.26)^{* * *}$ & $1.66(1.08 \text { to } 2.55)^{*}$ & $1.38(0.72$ to 2.65$)$ \\
\hline Single/never married & $1.56(0.96$ to 2.54$)$ & $2.22(1.26 \text { to } 3.89)^{* *}$ & $5.33(2.93 \text { to } 9.67)^{\star * *}$ \\
\hline \multicolumn{4}{|l|}{ Sexual orientation } \\
\hline Bisexual & $1.10(0.70$ to 1.74$)$ & $2.09(1.27 \text { to } 3.46)^{* *}$ & $5.87(3.50 \text { to } 9.85)^{* * *}$ \\
\hline Homosexual & $3.98(0.59$ to 26.70$)$ & $5.61(0.68$ to 46.49$)$ & 5.05 (0.47 to 54.57$)$ \\
\hline Non-white ethnicity $+\dagger$ & $0.35(0.21 \text { to } 0.58)^{* * *}$ & $0.22(0.11 \text { to } 0.46)^{* * *}$ & $0.11(0.03 \text { to } 0.35)^{* * *}$ \\
\hline \multicolumn{4}{|l|}{ Wealth quintile $\ddagger$} \\
\hline 2 & $0.97(0.71$ to 1.31$)$ & $0.83(0.55$ to 1.25$)$ & 0.90 (0.55 to 1.48$)$ \\
\hline 3 & 1.05 (0.77 to 1.43$)$ & 0.90 (0.59 to 1.37$)$ & $1.02(0.60$ to 1.74$)$ \\
\hline 4 & $0.83(0.60$ to 1.15$)$ & $1.08(0.71$ to 1.66$)$ & $0.74(0.42$ to 1.32$)$ \\
\hline 5 (richest) & $0.88(0.63$ to 1.23$)$ & 1.15 (0.74 to 1.77$)$ & $1.20(0.69$ to 2.10$)$ \\
\hline \multicolumn{4}{|l|}{ Smoking status§§ } \\
\hline Former smoker & $1.17(0.78$ to 1.73$)$ & $1.78(1.14 \text { to } 2.78)^{*}$ & $2.24(1.31 \text { to } 3.83)^{* *}$ \\
\hline Current smoker & 1.53 (1.13 to 2.07$)$ & $1.95(1.34 \text { to } 2.83)^{* * *}$ & $3.18(2.06 \text { to } 4.90)^{* * *}$ \\
\hline \multicolumn{4}{|l|}{ Alcohol intakeףी } \\
\hline Regularly & 1.23 (0.98 to 1.54$)$ & $2.20(1.58 \text { to } 3.06)^{* * *}$ & $1.16(0.78$ to 1.75$)$ \\
\hline Frequently & $1.59(1.23 \text { to } 2.07)^{\star *}$ & $3.16(2.18 \text { to } 4.56)^{* * *}$ & $2.17(1.39 \text { to } 3.40)^{* *}$ \\
\hline \multicolumn{4}{|l|}{ Physical activity††† } \\
\hline Moderately active at least once a week & $1.51(1.18 \text { to } 1.92)^{* *}$ & $1.26(0.90$ to 1.76$)$ & $1.68(1.08 \text { to } 2.60)^{*}$ \\
\hline Vigorously active at least once a week & $1.60(1.19 \text { to } 2.14)^{* *}$ & $1.74(1.19 \text { to } 2.55)^{* *}$ & $1.73(1.04 \text { to } 2.88)^{*}$ \\
\hline Limiting long-standing illness & $1.12(0.91$ to 1.38$)$ & $1.53(1.16 \text { to } 2.02)^{* *}$ & $1.58(1.10 \text { to } 2.26)^{*}$ \\
\hline
\end{tabular}

All figures are weighted for sampling probabilities and differential non-response.

${ }^{*} \mathrm{P}<0.05,{ }^{* *} p<0.01,{ }^{* * *} p<0.001$.

†Multivariable multinomial logistic regression was performed. $0-1$ sexual partners was the reference group in all analyses $(n=1198)$.

¥Unweighted sample sizes. Models were performed on complete cases and as such the analysed sample number differs from the number included in the bivariate analyses.

§Reference category: married/cohabiting.

IReference category: heterosexual.

t+Reference category: white.

‡¥Reference category: 1 (poorest).

$\S \S$ Reference category: never smoker.

११(Reference category: never/rarely.

†† Reference category: inactive.

processes and may increase chances of unplanned sexual encounters.

Homosexuality predicted a higher number of lifetime sexual partners in men only. The literature is mixed on this topic, with some studies indicating that gay men have a higher number of sexual partners compared with heterosexual men and some studies observing a similar prevalence. ${ }^{35}$ The inconsistency in the data on the number of sexual partners of gay men probably reflects flaws in the sampling techniques of earlier studies (eg, recruiting subjects in gay bars) and their completion before the HIV epidemic. ${ }^{35}$ However, the present study does suggest that gay men do have a greater number of sexual partners in their lifetime. This is of clinical importance, given that gay men are a key population with a high prevalence of HIV $^{35}$ and a greater number of sexual partners is known to increase the risk of HIV transmission.

In the present study, being in the highest and lowest quintiles of wealth was associated with a higher number of previous sexual partners in men but not in women. Socioeconomic status is an established predictor of divorce, with higher divorce rates among those from the lowest and highest socioeconomic groups. ${ }^{36}$ This ties in with the finding that those who are not married have a higher number of sexual partners. 
Women from white ethnic backgrounds reported a higher number of lifetime sexual partners than those from other ethnicities. A plausible explanation is differences in cultural norms between the ethnicities. For example, a large proportion of Asians and only a small proportion of white individuals residing in the UK follow Islam. ${ }^{37}$ For those who follow Islam, sexual intercourse between unmarried men and women is forbidden and thus this population is likely to have a low number of lifetime sexual partners. It is not clear why an association with ethnicity was only observed in women; further research is required to explore this in greater detail. Another factor that was found to predict number of sexual partners in women only was vigorous physical activity. Women who reported engaging in moderate and vigorous physical activity at least weekly were more likely to report a higher number of lifetime sexual partners than those who were less active. Vigorous physical activity is usually achieved via participating in sport. ${ }^{38}$ Sport participation has been shown to track across the lifespan ${ }^{39}$ and may provide a setting for social interaction, thus increasing the potential to meet a greater number of potential sexual partners. However, further research is required to confirm or refute this hypothesis. Moreover, physical activity has been shown to lower levels of depression and depression has been shown to be associated with higher levels of sexual problems. Absence of limiting long-standing illness was associated with a higher number of sexual partners in women. Women who do not have such illnesses may have had greater opportunity across the lifespan for greater social interaction (eg, via sports participation; those with limiting longstanding illness are less likely to participate in sport) and increasing one's opportunity to meet a greater number of sexual partners. Finally, women who were bisexual had a higher number of lifetime sexual partners than those who were heterosexual. A plausible explanation for this finding is elusive and further res earch is needed.

This is the first study to identify sociodemographic and behavioural correlates of the number of lifetime sexual partners in an older sample. Strengths of the study include the large, representative sample and data on a wide range of potential correlates. However, findings from the present study must be interpreted in light of its limitations. All measures were self-reported which may have introduced reporting or recall bias (particularly in relation to lifetime number of sexual partners). However, the item on number of sexual partners was included in a paper-based questionnaire rather than in the face-to-face interview, and it was made clear to participants that survey responses would remain anonymous. The sample was almost exclusively white so findings may not generalise to other ethnic groups in which attitudes towards sex may differ. While the measure of smoking took into account historical behaviour by including a category for ex-smokers, data on alcohol intake and physical activity only reflected participants' current behaviour. The predictive power of these variables in determining number of sexual partners over the life course may therefore have been over- or underestimated. Longitudinal cohort studies that collect measures of these behaviours throughout the life course could assess prospective relationships by asking participants to report their lifetime number of sexual partners in future waves of data collection. Finally, the current data were not able to ascertain for each participant when during the lifespan the period at which the greatest number of sexual partners were acquired. For some participants it is possible that they only had a very high number of sexual partners when adolescents, others middle age, and for some old age.

In conclusion, the present study has identified a number of sociodemographic and behavioural correlates of lifetime sexual partners. This information may help health practitioners to identify individuals who are at greatest risk of STIs and their associated health complications across the life course. Moreover, findings from the present study could also benefit younger adults through targeted interventions to educate groups at risk of having a high number of sexual partners about the risks associated with doing so, and the practice of safe sex.

\section{Author affiliations}

'Department of Behavioural Science and Health, University College London (UCL), London, UK

${ }^{2}$ Center for Public Health, Medical University Vienna, Vienna, Austria

${ }^{3}$ Neuroscience Institue, University of Padova, Padova, Italy

${ }^{4}$ Research and Development Unit, Universitat de Barcelona, Barcelona, Spain ${ }^{5}$ Faculty of Sport Sciences, University of Murcia, Murcia, Spain

${ }^{6}$ Social and Preventive Medicine, Medical University Vienna, Vienna, Austria ${ }^{7}$ Department of Geriatric Medicine, Bezmialem Vakif University, Istanbul, Turkey ${ }^{8}$ Cambridge Centre for Sport and Exercise Sciences, Anglia Ruskin University, Cambridge, UK

Acknowledgements The authors acknowledge their previous publication that used the same dataset (ELSA): Jackson S, Firth J, Veronese N, Stubbs B, Koyanagi A, Yang L, Smith L. Decline in sexuality and wellbeing in older adults: a population based study. Journal of Affective Disorders 2018;245:912-917.

Contributors SJ and LS conceived the idea. SJ carried out statistical analyses. SJ and LS interpreted the findings. SJ and LS drafted the manuscript. All authors provided extensive comments on the manuscript. All authors approved the final manuscript before submission.

Funding The authors have not declared a specific grant for this research from any funding agency in the public, commercial or not-for-profit sectors.

Competing interests None declared.

Patient consent for publication Not required.

Provenance and peer review Not commissioned; externally peer reviewed.

Open access This is an open access article distributed in accordance with the Creative Commons Attribution Non Commercial (CC BY-NC 4.0) license, which permits others to distribute, remix, adapt, build upon this work non-

commercially, and license their derivative works on different terms, provided the original work is properly cited, appropriate credit is given, any changes made indicated, and the use is non- 
commercial. See: http://creativecommons.org/licenses/by-nc/4. $0 /$.

\section{REFERENCES}

1 Kelley SS, Borawski EA, Flocke SA, et al. The role of sequential and concurrent sexual relationships in the risk of sexually transmitted diseases among adolescents. J Adolesc Health 2003;32:296-305.

2 Boyer CB, Shafer M, Wibbelsman CJ, et al. Associations of sociodemographic, psychosocial, and behavioral factors with sexual risk and sexually transmitted diseases in teen clinic patients. J Adolesc Health 2000;27:102-11.

3 Stergachis A, Scholes D, Heidrich FE, et al. Selective screening for Chlamydia trachomatis infection in a primary care population of women. Am J Epidemiol 1993;138:143-53.

4 Karlsson R, Jonsson M, Edlund K, et al. Lifetime number of partners as the only independent risk factor for human papillomavirus infection: a population-based study. Sex Transm Dis 1995;22:119-27.

5 Koblin BA, Husnik MJ, Colfax G, et al. Risk factors for HIV infection among men who have sex with men. AIDS 2006;20:731-9.

6 Samkange-Zeeb FN, Spallek L, Zeeb H. Awareness and knowledge of sexually transmitted diseases (STDs) among school-going adolescents in Europe: a systematic review of published literature. BMC Public Health 2011;11:727.

7 Muñoz N, Castellsagué X, de González AB, et al. Chapter 1: HPV in the etiology of human cancer. Vaccine 2006;24:S1-10.

8 Di Bisceglie AM. Hepatitis B and hepatocellular carcinoma. Hepatology 2009;49:S56-60.

9 Mesri EA, Cesarman E, Boshoff C. Kaposi's sarcoma herpesvirus/human herpesvirus-8 (KSHV/HHV8), and the oncogenesis of Kaposi's sarcoma. Nat Rev Cancer 2010;10:707-19.

10 Murphy EL, Hanchard B, Figueroa JP, et al. Modelling the risk of adult T-cell leukemia/lymphoma in persons infected with human T-lymphotropic virus type I. Int J Cancer 1989;43:250-3.

11 Weström LV. Sexually transmitted diseases and infertility. Sex Transm Dis 1994;21:S32-7.

12 Hitchcock PJ. Women, children and STDs: addressing the other STD epidemic. Opinion. Aidscaptions 1996;3:37-40.

13 Glasier A, Gülmezoglu AM, Schmid GP, et al. Sexual and reproductive health: a matter of life and death. Lancet 2006;368:1595-607.

14 Ebrahim SH, McKenna MT, Marks JS. Sexual behaviour: related adverse health burden in the United States. Sex Transm Infect 2005;81:38-40.

15 Owusu-Edusei K, Chesson HW, Gift TL, et al. The estimated direct medical cost of selected sexually transmitted infections in the United States, 2008. Sex Transm Dis 2013;40:197-201.

16 Grunbaum JA, Kann L, Kinchen SA, et al. Youth risk behavior surveillance - United States, 2001. Morb Mortal Wkly Rep Surveill Summ Wash DC 2002;51:1-62.

17 Valois RF, Oeltmann JE, Waller J, et al. Relationship between number of sexual intercourse partners and selected health risk behaviors among public high school adolescents. J Adolesc Health 1999;25:328-35.

18 Mitchell KR, Mercer CH, Ploubidis GB, et al. Sexual function in Britain: findings from the third National Survey of Sexual Attitudes and Lifestyles (Natsal-3). The Lancet 2013;382:1817-29.

19 Cancer Research UK. Cancer incidence by age. 2018 http://www. cancerresearchuk.org/cancer-info/cancerstats/incidence/age/
20 Butt AA, Dascomb KK, DeSalvo KB, et al. Human immunodeficiency virus infection in elderly patients. South Med J 2001;94:397-400.

21 Steptoe A, Breeze E, Banks J, et al. Cohort profile: the English Longitudinal Study of Ageing. Int J Epidemiol 2013;42:1640-8.

22 Lee DM, Nazroo J, O'Connor DB, et al. Sexual health and well-being among older men and women in England: findings from the English Longitudinal Study of Ageing. Arch Sex Behav 2016;45:133-44.

23 Banks J, Karlsen S, Oldfield Z. Socio-economic position. 2003 http://discovery.ucl.ac.uk/15366/1/15366.pdf

24 Demakakos P, Hamer M, Stamatakis E, et al. Low-intensity physical activity is associated with reduced risk of incident type 2 diabetes in older adults: evidence from the English Longitudinal Study of Ageing. Diabetologia 2010;53:1877-85.

25 Hamer M, Molloy GJ, de Oliveira C, et al. Leisure time physical activity, risk of depressive symptoms, and inflammatory mediators: the English Longitudinal Study of Ageing. Psychoneuroendocrinology 2009;34:1050-5.

26 Kann L, Kinchen SA, Williams BI, et al. Youth risk behavior surveillance - United States, 1997. J Sch Health 1998;68:355-69.

27 Johannes CB, Araujo AB, Feldman HA, et al. Incidence of erectile dysfunction in men 40 to 69 years old: longitudinal results from the Massachusetts male aging study. J Urol 2000;163:460-3.

28 Muehlenhard CL, McCoy ML. Double standard/double bind: the sexual double standard and women's communication about sex. Psychol Women Q 1991;15:447-61.

29 Mitchell KR, Mercer CH, Prah P, et al. Why do men report more opposite-sex sexual partners than women? Analysis of the gender discrepancy in a British national probability survey. J Sex Res 2018.

30 Schoen R, Urton W, Woodrow K, et al. Marriage and divorce in twentieth century American cohorts. Demography 1985;22:101-14.

31 Fisher JC, Bang H, Kapiga SH. The association between HIV infection and alcohol use: a systematic review and metaanalysis of African studies. Sex Transm Dis 2007;34:856-63.

32 Kalichman SC, Simbayi L, Jooste S, et al. Sensation seeking and alcohol use predict HIV transmission risks: prospective study of sexually transmitted infection clinic patients, Cape Town, South Africa. Addict Behav 2008;33:1630-3.

33 Fernie G, Cole JC, Goudie AJ, et al. Risk-taking but not response inhibition or delay discounting predict alcohol consumption in social drinkers. Drug Alcohol Depend 2010;112:54-61.

34 Byrnes JP, Miller DC, Schafer WD. Gender differences in risk taking: a meta-analysis. Psychol Bull 1999;125:367-83.

35 Friedman RC, Downey JI. Homosexuality. N Engl J Med Overseas Ed 1994;331:923-30.

36 Amato PR, Previti D. People's reasons for divorcing: gender, social class, the life course, and adjustment. J Fam Issues 2016;24:602-26.

37 Muslim ethnicities. Centre for the Study of Islam in the UK. 2015 http://sites.cardiff.ac.uk/islamukcentre/rera/onlineteaching-resources/muslims-in-britain-online-course/module-3communities/diversities/muslim-ethnicities/

38 Ainsworth BE, Haskell WL, Leon AS, et al. Compendium of physical activities: classification of energy costs of human physical activities. Med Sci Sports Exerc 1993;25:71-80.

39 Smith L, Gardner B, Aggio D, et al. Association between participation in outdoor play and sport at 10 years old with physical activity in adulthood. Prev Med 2015;74:31-5. 